\title{
Milk skimming, heating, acidification, lysozyme, and rennet affect the pattern, repeatability, and predictability of milk coagulation properties and of curd-firming model parameters: A case study of Grana Padano
}

\author{
G. Stocco, ${ }^{*}$ C. Cipolat-Gotet,${ }^{*}$ A. Cecchinato, ${ }^{* 1}$ L. Calamari, $\dagger$ and G. Bittante ${ }^{*}$ \\ *Department of AgroNomy, Food, Natural resources, Animals and Environment (DAFNAE), University of Padova, 35020 Legnaro, Italy \\ †Istituto di Zootecnica, Università Cattolica del sacro Cuore, 29122 Piacenza, Italy
}

\begin{abstract}
Milk coagulation properties are used to evaluate the cheesemaking aptitude of milk samples. No international standard procedure exists, although laboratories often mimic the production of a full-fat fresh cheese for milk coagulation properties. Questions have arisen about the predictability of such a procedure for different types of cheese production. The aim of this study was to establish a procedure mimicking the production conditions of a long-ripened hard cheese, taking Protected Designation of Origin Grana Padano as a case study. With respect to the traditional conditions (standard procedure; SP), the Grana Padano procedure (GP) modifications were the use of standardized milk, coagulation lower temperature, previous milk acidification, lysozyme addition, and rennet type. Each modification was tested in turn versus the SP and also all together in the GP. Another 3 tests were carried out: SP on naturally creamed milk, SP with double the quantity of rennet, and a simplified GP on a full-fat milk sample. The 10 procedures were tested on 2 subsamples with 2 replicates each and were repeated using individual milk samples from 15 dualpurpose Simmental cows in 4 sessions for a total of 600 tests. Two Formagraph instruments (Foss Electric A/S, Hillerød, Denmark) measuring curd firmness every $15 \mathrm{~s}$ were used, prolonging test duration to $60 \mathrm{~min}$ to obtain 5 traditional single-point milk coagulation properties and 3 parameters of the curd firming model using all 240 points recorded for each replicate. The 8 traits of each replicate were analyzed according to a mixed model with fixed effects of 4 sessions, 10 treatments, 2 instruments, and 16 microvats, and random effects of 15 animals and 300 subsamples. Compared with the SP, the coagulation and curd firming was slowed by low temperature and was accelerated by acidification and by adding a double amount of rennet; natural creaming, fat standardization, and rennet with $5 \%$ pepsin
\end{abstract}

Received November 23, 2014.

Accepted April 19, 2015.

${ }^{1}$ Corresponding author: alessio.cecchinato@unipd.it. affected only some traits, whereas lysozyme addition affected none. Combination of all modifications tended to compensate for each of their effects, resulting in similar average patterns between GP and SP. Modifications to repeatability were found for all traits with the exception of 2. The ability of the SP to predict GP, tested through correlations between procedures, was not very high. Whereas SP is used for both research and in the dairy industry, better results for Grana Padano cheesemaking can only be achieved by adopting specific, more complex, and labor-intensive procedures at the research level or, possibly, by specific calibrations through Fourier-transform infrared spectroscopy at the industry level.

Key words: milk coagulation properties, cheesemaking, Grana Padano, curd firming modeling

\section{INTRODUCTION}

Milk coagulation properties (MCP) are important for the dairy industry, and many studies have confirmed that MCP analysis provides significant information regarding milk quality, cheese processing, and cheese yield both in the laboratory (Walsh et al., 1998; Wedholm et al., 2006; Alipanah and Kalashnikova, 2007) and in industry (Buchberger and Dovč, 2000; Johnson et al., 2001; Summer et al., 2003). In addition, the renneting characteristics of milk influence the sensory properties and typical features of a given cheese (Martin et al., 1997). For this reason, MCP are important for Protected Designation of Origin (PDO) cheeses (Mariani and Battistotti, 1999; Bertoni et al., 2005), and in some cases (e.g., Trentingrana, a specific Grana Padano cheese produced in the mountains of Trento province) they are used in the milk payment system to reward or penalize milk producers (Calamari et al., 2005; Bittante et al., 2011b). Moreover, MCP have been proposed to be included in selection objectives for dairy cows (Bittante et al., 2012; Cecchinato et al., 2013).

Traditionally, MCP are measured with a lactodynamograph. In Italy, a common analytical procedure has been proposed by the Italian Association of Animal 
Production Science (ASPA Commission, 1995), but different studies still employ different analytical conditions (as reviewed by Bittante et al., 2012), and no international standard exists. Analytical conditions often tend to simplify the cheesemaking process and frequently concern the processing of full-fat milk without acidification or starter bacteria inocula and use temperature and rennet type and concentration generally associated with fresh cheese production. The operating conditions for producing different cheeses are numerous and complex and have a marked effect on the quality of the final product (Law and Tamine, 2010). It is arguable whether the lactodynamographic conditions can mimic the technology used for making a specific cheese. Several researchers have studied the effect of individual factors (skimming, heating temperature, acidification, calcium addition, type and quantity of rennet, and so on) on MCP (Lucey, 2002; Nájera et al., 2003; Mishra et al., 2005), but without comparing specific procedures for different cheeses.

An example of a cheesemaking procedure that is very different to that of fresh full-fat cheeses is Grana Padano, a cooked, extra-hard, long-ripened cheese made in northern Italy from partially skimmed raw milk. The several steps involved in producing this cheese have been honed over the centuries and are now regulated by production procedures approved by the European Union and which grant Grana Padano PDO status. These days, Grana Padano has the highest production rate of any PDO cheese in the European Union (CLAL, 2014) and is therefore a suitable case study to represent this category of cheeses.

As the simplified procedures adopted by different laboratories are for fresh cheese production, the general aim of our study was to compare the standard laboratory method with a procedure mimicking long-ripening hard cheese production. The specific aims were (1) to fine tune a lactodynamographic procedure simulating Grana Padano cheesemaking; (2) to evaluate the effect of each different step in the Grana Padano procedure; (3) to evaluate the combined effects of the Grana Padano procedure and compare it with the standard procedure; (4) to evaluate a potential simplified Grana Padano procedure; (5) to study the effect of individual procedure modifications and their combination on the repeatability of lactodynamographic procedures; and (6) to analyze the predictability of Grana Padano MCP with standard or simplified Grana Padano procedures.

\section{MATERIALS AND METHODS}

\section{Milk Sampling}

Fifteen dual-purpose Simmental cows reared at the Lucio Toniolo Experimental Farm of the University of
Padova (Legnaro, Italy) were selected to represent different parities ( 1 to 3$)$, lactation stages $(111 \pm 22 \mathrm{~d}$ ), and milk yield $(27.9 \pm 6.2 \mathrm{~kg} / \mathrm{d})$ and to represent a wide variation in the quality and cheesemaking aptitude of the milk. Cows were sampled once during morning milking $(2.5 \mathrm{~L} / \mathrm{cow})$ over 4 sampling sessions (3-4 cows per session). Samples were immediately placed at $10^{\circ} \mathrm{C}$ and taken to the nearby Milk Quality Laboratory of the Department of Agronomy, Food, Natural Resources, Animals and Environment (DAFNAE) of the University of Padova. An aliquot of $500 \mathrm{~mL}$ was taken from each milk sample and placed in a glass tube for creaming at $10^{\circ} \mathrm{C}$. The following morning the 2 aliquots were treated as described herein to obtain 20 subsamples per cow (300 in total) for the 10 experimental treatments across the 2 different lactodynamographs. Each subsample was replicated twice to obtain a total of 600 recorded data files. In addition, an aliquot (50 $\mathrm{mL}$ ) of each subsample was used to determine chemical composition, $\mathrm{SCC}$, and $\mathrm{pH}$.

\section{Experimental Treatments}

Table 1 shows the different lactodynamographic procedures characterizing the 10 experimental treatments, which include 2 extreme and 8 intermediate procedures. The first extreme treatment is the lactodynamographic procedure adopted by DAFNAE, here defined as the standard $(\mathbf{S})$ procedure, which is based on the procedure proposed by the ASPA Commission (1995); this mimics, in a very simplified way, the technology often used for the production of fresh cheeses (Cipolat-Gotet et al., 2012) and is similar to the large majority of procedures adopted by other research groups, as reviewed by Bittante et al. (2012). The other extreme treatment is a laboratory simulation of the main features characterizing Grana Padano cheesemaking, here defined as the Grana Padano procedure. As the 2 extreme treatments differed in several factors, 7 other conditions were devised, allowing us to analyze the effects of individual modifications to the Grana Padano procedure with respect to the standard. The first variation was partial skimming of the milk sample by natural creaming ( $\mathrm{S}+$ natural creaming); the second was standardization of the milk fat-to-casein ratio obtained by mixing full-fat and creamed subsamples together $(\mathrm{S}+$ fat standardization); the third was reduction of milk temperature during the analyses from 35 to $32^{\circ} \mathrm{C}(\mathrm{S}+$ low temperature); the fourth was acidification of the milk subsample to $6.38 \mathrm{pH}(\mathrm{S}+$ acidification); the fifth was the addition of lysozyme to the milk before the analyses ( $\mathrm{S}+$ lysozyme); the sixth was substituting the rennet preparation used in the standard procedure (rennet with $20 \%$ pepsin) with one with a lower pepsin 
Table 1. Description of the 10 experimental treatments obtained by modifying individually and all together the lactodynamographic testing conditions from the standard procedure to those specific to Grana Padano cheese

\begin{tabular}{|c|c|c|c|c|c|c|}
\hline \multirow[b]{2}{*}{ Experimental treatment } & \multicolumn{6}{|c|}{ Lactodynamographic testing conditions: } \\
\hline & Creaming & $\begin{array}{c}\text { Temperature, } \\
{ }^{\circ} \mathrm{C}\end{array}$ & $\begin{array}{c}\text { Acidification } \\
\text { pH }\end{array}$ & $\begin{array}{l}\text { Lysozyme } \\
\text { addition }\end{array}$ & $\begin{array}{c}\text { Rennet type } \\
\text { pepsin, \% }\end{array}$ & $\begin{array}{c}\text { Rennet amount, } \\
\text { IMCU/L }\end{array}$ \\
\hline Standard (S) & No & 35 & Native & No & 20 & 51 \\
\hline $\mathrm{S}+$ natural creaming & Yes & 35 & Native & No & 20 & 51 \\
\hline $\mathrm{S}+$ fat standardization & Partial $^{1}$ & 35 & Native & No & 20 & 51 \\
\hline $\mathrm{S}+$ low temperature & $\mathrm{No}$ & 32 & Native & No & 20 & 51 \\
\hline $\mathrm{S}+$ acidification & No & 35 & 6.38 & No & 20 & 51 \\
\hline $\mathrm{S}+$ lysozyme & No & 35 & Native & $0.18 \mathrm{~g} / \mathrm{L}$ & 20 & 51 \\
\hline $\mathrm{S}$ with rennet $5 \%$ pepsin & No & 35 & Native & No & 5 & 51 \\
\hline S with double rennet $20 \%$ pepsin & No & 35 & Native & No & 20 & 102 \\
\hline Grana Padano & Partial & 32 & 6.38 & $0.18 \mathrm{~g} / \mathrm{L}$ & 5 & 51 \\
\hline Simplified Grana Padano ${ }^{2}$ & No & 32 & 6.38 & $0.18 \mathrm{~g} / \mathrm{L}$ & 5 & 51 \\
\hline
\end{tabular}

${ }^{1}$ Partial $=$ creamed and full-fat milk were mixed to obtain a $1: 1$ fat:CN ratio.

${ }^{2} \mathrm{~A}$ simplified procedure circumventing creaming and mixing of creamed and full-fat milk, the most time-consuming laboratory operations.

content (rennet with $5 \%$ pepsin), often used for PDO long-ripened cheeses (S with rennet $5 \%$ pepsin); whereas the seventh consisted in doubling the concentration of rennet with $20 \%$ pepsin (S with double rennet $20 \%$ ), which was not directly related to the Grana Padano cheesemaking procedure but was included to assess the effects of rennet $5 \%$ pepsin concentration compare with rennet $20 \%$ pepsin.

The Grana Padano treatment was a combination of all these modifications $(\mathrm{S}+$ fat standardization + low temperature + milk acidification + lysozyme addition + rennet $5 \%$ pepsin). As fat standardization (natural creaming of a subsample, fat and casein analysis of fullfat and skim milk subsamples, then mixing them in the proportions needed to reach the desired fat-to-casein ratio) is the most labor-intensive variation, constraining laboratory use of the Grana Padano procedure, a tenth simplified treatment (simplified Grana Padano) was created by applying all the Grana Padano modifications to full-fat milk subsamples (Table 1).

\section{Standard Procedure}

The morning after collection of the milk samples, 2 subsamples per cow (1 per instrument) with 2 replicates of each $(10 \mathrm{~mL})$ were preheated to $35^{\circ} \mathrm{C}$ (for $15 \mathrm{~min}$ ). Then, $200 \mu \mathrm{L}$ of bovine rennet with $20 \%$ pepsin- $80 \%$ chymosin [Naturen Plus 215 Hansen, 215 international milk clotting units (IMCU)/mL; Pacovis Amrein AG, Bern, Switzerland] solution diluted to $1.2 \%$ in distilled water was added to each subsample (51 IMCU/L). The milk was not submitted to any other pretreatment and coagulation temperature was maintained at $35^{\circ} \mathrm{C}$. The duration of the test was $60 \mathrm{~min}$.

\section{S + Natural Creaming}

Milk was skimmed by natural creaming. An aliquot of $500 \mathrm{~mL}$ was taken from a sample of milk from each cow $(2.5 \mathrm{~L})$ and put into a glass tube with a tap on the bottom. Natural creaming occurred at $10^{\circ} \mathrm{C}$ for $22 \mathrm{~h}$, after which the partly skim milk $(400 \mathrm{~mL})$ was slowly separated from the cream $(100-\mathrm{mL}$ supernatant fraction) through the tap on the bottom. One subsample per instrument with 2 replicates was analyzed under the same experimental conditions as the standard procedure.

\section{S + Fat Standardization}

An aliquot of a naturally creamed sample and an aliquot of a full-fat milk sample from each cow were analyzed for fat and casein content and a quantity of the different aliquots needed to obtain a fat-to-casein ratio of about 1:1 were mixed together. If the full-fat milk aliquot of a given cow had a fat-to-casein ratio equal to or lower than 1:1, it was not mixed with the skimmed aliquot before the lactodynamographic analyses. Having obtained fat standardized milk, lactodynamographic analysis conditions were the same as the standard procedure.

\section{S + Low Temperature}

An aliquot of each full-fat milk sample was preheated to $32^{\circ} \mathrm{C}$ (for $15 \mathrm{~min}$ ) instead of $35^{\circ} \mathrm{C}$ and $200 \mu \mathrm{L}$ of the same bovine rennet solution used in the standard treatment (rennet with $20 \%$ pepsin) was added to the milk. Coagulation temperature was maintained at $32^{\circ} \mathrm{C}$, whereas all other conditions were the same as the standard procedure. 


\section{$S+$ Acidification}

An aliquot of $100 \mathrm{~mL}$ of full-fat milk was taken from the samples of milk from each cow and acidified using $10 \%$ citric acid solution diluted in distilled water. For each analysis, milk subsamples $(100 \mathrm{~mL} /$ animal $)$ were preheated in a water bath to $20^{\circ} \mathrm{C}$. Once this temperature was reached (in 15-20 min), each milk subsample was put into a beaker with a magnetic body and placed on a magnet plate to keep it under constant agitation. Initial $\mathrm{pH}$ was measured (portable $\mathrm{pH}$ meter Crison Basic 25; Crison Instruments SA, Barcelona, Spain), then a constant quantity of citric acid solution $(20 \mu \mathrm{L})$ was repeatedly added until a $\mathrm{pH}$ of 6.38 was reached. Different quantities of acid solution (from 80 to $220 \mu \mathrm{L}$ ) were added to each subsample according to the initial $\mathrm{pH}$ and buffering capacity. The treated subsamples were then moved to the racks of the 2 instruments to undergo the same lactodynamographic analysis as the standard procedure.

\section{S + Lysozyme}

A quantity of $18 \mathrm{mg} / \mathrm{L}$ of lysozyme hydrochloride, previously weighed in a small glass tube, was added to the individual full-fat milk subsamples $(100 \mathrm{~mL})$ and gently mixed. The treated subsamples were then moved to the racks of the instruments to undergo the same lactodynamographic analysis as the standard procedure.

\section{S with Rennet 5\% Pepsin}

Rennet with a low pepsin content was chosen in accordance with the production specifications of Grana Padano PDO cheese, which required the use of natural calf rennet with a chymosin content of $\geq 95 \%$ and pepsin $\leq 5 \%$. Liquid calf rennet (Naturen Extra 220 Hansen, $210 \mathrm{IMCU} / \mathrm{mL}$ ) was used for this treatment and the enzymatic solution was prepared with the same IMCU per liter of milk as the standard treatment (51 IMCU/L of milk). Lactodynamographic analysis conditions were the same as the standard procedure except for the type of rennet employed.

\section{S with Double Rennet with $20 \%$ Pepsin}

A double concentration of Rennet $20 \%$ pepsin (102 IMCU/L of milk) was added to each subsample in this treatment. The lactodynamographic analysis conditions were the same as the standard treatment, except for the quantity of rennet employed.

\section{Grana Padano Procedure}

In this treatment, a simplified laboratory simulation of the normal procedures for Grana Padano PDO cheese manufacture was obtained by applying all the following previously described variations to the standard procedure to each subsample. Variations included natural creaming of an aliquot, preparation of standardized milk subsamples with a fat-to-casein ratio of 1:1, milk acidification to $\mathrm{pH} 6.38\left(20^{\circ} \mathrm{C}\right)$, addition of lysozyme $(18 \mathrm{mg} / \mathrm{L})$, milk preheating to $32^{\circ} \mathrm{C}$, addition of rennet with $5 \%$ pepsin (51 IMCU/L of milk), and coagulation temperature maintained at $32^{\circ} \mathrm{C}$.

\section{Simplified Grana Padano Procedure}

The procedure for this treatment was the same as the Grana Padano procedure, with the single exception of using full-fat instead of standardized milk samples.

\section{Chemical and Physical Analyses}

Analyses were performed at the DAFNAE Milk Quality Laboratory of the University of Padova the day after collection of the samples. During storage the milk was kept at $10^{\circ} \mathrm{C}$. All subsamples were analyzed for $\mathrm{pH}$ (portable $\mathrm{pH}$ meter Crison Basic 25; Crison Instruments SA) with a combined electrode (Crison, $5051 \mathrm{~T}$ ) and SCC (Fossomatic MiNor, Foss Electric A/S, Hillerød, Denmark); fat, protein, casein, and TS contents were measured by Milkoscan FT2 infrared analyzer (Foss Electric A/S), calibrated according to the reference methods [ISO 1211/IDF for fat (ISO-IDF, 2010); ISO 8968-2/IDF 20-2 for protein (ISO-IDF, 2014); ISO 17997-1/IDF 29-1 for casein (ISO-IDF, 2004)] and adjusted for slope or intercept monthly using 10 reference samples provided by Istituto Zooprofilattico Sperimentale della Lombardia e dell'Emilia Romagna (Brescia, Italy). Milk coagulation properties were measured using Formagraph lactodynamographs (2 modules; Foss Electric A/S) with pendula calibration done before each session of the trial. Milk SCC was log-transformed to SCS (Ali and Shook, 1980). Traditional [rennet coagulation time (RCT), time interval between gelation and attainment of curd firmness of $20 \mathrm{~mm}\left(\mathbf{k}_{\mathbf{2 0}}\right)$, and curd firmness at 30 min after rennet addition $\left(\mathbf{a}_{\mathbf{3 0}}\right)$ ] and time to curd firmness at 45 and 60 min after rennet addition $\left(\mathbf{a}_{45}\right.$ and $\mathbf{a}_{60}$, respectively) single-point measurements of each subsample replicate were obtained directly from the instruments. The data file with 240 curd firmness (CF) observations (1 every $15 \mathrm{~s}$ for $60 \mathrm{~min}$ of the test) for each replicate was also extracted. 


\section{Modeling of MCP}

The 3-parameter model used to describe CF change over time $\left(\mathbf{C F}_{t}\right)$ is described in detail by Bittante (2011). It uses all the information available for estimating the 3 parameters, which, unlike traditional MCP, are not single-point measurements. The model tested was

$$
\mathrm{CF}_{t}=\mathrm{CF}_{\mathrm{P}} \times\left[1-\mathrm{e}^{-\mathrm{kCF} \times(t-\mathrm{RCTeq})}\right],
$$

where $\mathrm{CF}_{t}$ is curd firmness at time $t(\mathrm{~mm}) ; \mathbf{C F}_{\mathbf{P}}$ is the asymptotical potential value of $\mathrm{CF}$ at an infinite time $(\mathrm{mm}) ; \mathbf{k}_{\mathbf{C F}}$ is the curd-firming instant rate constant (\% $\times \min ^{-1}$ ); and $\mathbf{R C T}_{\text {eq }}$ is RCT estimated by $\mathrm{CF}_{t}$ equation on the basis of all data points (min). The $\mathrm{CF}_{\mathrm{P}}$ is conceptually independent from test duration and is not intrinsically dependent on RCT (unlike $\mathrm{a}_{30}$ ). The parameter $\mathrm{k}_{\mathrm{CF}}$ describes the shape of the curve from the time of milk gelation to infinity and is conceptually different from $\mathrm{k}_{20}$ as it uses all available information. The 4-parameter model, which also includes syneresis instant rate constant (Bittante et al., 2013), was not used in this study because a preliminary view of the $\mathrm{CF}_{t}$ data did not show any appreciable decrease in $\mathrm{CF}$ in the final part of the curve.

\section{Statistical Analysis}

Experimental data were analyzed using a MIXED procedure (SAS Institute Inc., Cary, NC), in accordance with the following model:

$$
\begin{gathered}
\mathrm{y}_{\mathrm{ijklmno}}=\mu+\text { session }_{\mathrm{i}}+\text { treatment }_{\mathrm{j}}+\text { instrument }_{\mathrm{k}} \\
+ \text { pendulum }_{\mathrm{l}}\left(\text { instrument }_{\mathrm{k}}+\text { animal }_{\mathrm{m}}(\text { session })_{\mathrm{i}}\right. \\
+ \text { subsample }_{\mathrm{n}}(\text { animal })_{\mathrm{m}}+\varepsilon_{\mathrm{ijk} \mathrm{lmno}}
\end{gathered}
$$

where $\mathrm{y}_{\mathrm{ijklmno}}$ is the observed trait (RCT, $\mathrm{k}_{20}, \mathrm{a}_{30}, \mathrm{a}_{45}$, $\left.\mathrm{a}_{60}, \mathrm{RCT}_{\mathrm{eq}}, \mathrm{CF}_{\mathrm{P}}, \mathrm{k}_{\mathrm{CF}}\right) ; \mu$ is the overall intercept of the model; $\operatorname{session}_{\mathrm{i}}$ is the fixed effect of the ith date of analysis (4 sessions); treatment ${ }_{j}$ is the fixed effect of the jth experimental lactodynamographic procedure (10 treatments); instrument ${ }_{\mathrm{k}}$ is the fixed effect of the kth instrument (2 modules); pendulum ${ }_{1}$ (instrument) $)_{\mathrm{k}}$ is the fixed effect of the lth pendulum ( 8 pendula) within the kth instrument (2 modules); $\operatorname{animal}_{\mathrm{m}}(\mathrm{session})_{\mathrm{i}}$ is the random effect of the mth animal (15 animals) within the ith session of analysis; subsample $_{\mathrm{n}}(\text { animal })_{\mathrm{m}}$ is the random effect of the nth subsample (20 subsamples per animal, treatment, and instrument combined) within the ith animal; $\varepsilon_{\mathrm{ijklmno}}$ is the random effect of oth replicate within subsample (2 replicates per subsample), and corresponds to the random residual $N \sim\left(0, \sigma_{e}^{2}\right)$. where $\sigma^{2}$ is the residual variance.

Contrasts between the least squares means of each treatment and the least squares means of the standard treatment were calculated for each trait. Levene's test was performed to assess heteroskedasticity with respect to the effect of the experimental treatments on residual variance. As heteroskedasticity was significant for several traits, log-transformation was applied to evaluate possible improvements in homoscedasticity. However, as significant differences remained for some traits, untransformed dependent variables were chosen for statistical analysis, taking into account the robustness of mixed procedures and the advantage of having linear least squares means. To take into account the heterogeneity of residual variances induced by experimental treatments (differences in the repeatability of the analytical procedure), the simple correlations between the first and second replicates of each subsample within treatment were calculated as indicators of analytical repeatability. In addition, because of the precision of standard or simplified Grana Padano procedures as predictors of the Grana Padano procedure (as evidenced by nonsignificant differences between their respective LSM), the accuracy of standard or simplified Grana Padano procedures as predictors of the Grana Padano procedure was estimated from correlations between the results obtained for each subsample within these 3 procedures. These correlations were computed using the averages of the 2 replicates of each subsample, but also using the individual value of the first replicate of each subsample (to correctly compare these correlations with those between replicates).

\section{RESULTS}

\section{Chemical Composition of Milk Subsamples}

Quality traits of milk samples used in the trials are summarized in Table 2. Fat content was $3.79 \pm 1.03 \%$ for the standard treatment and was very similar in the other full-fat milk subsamples. Natural creaming decreased fat content by an average of $56 \%$ (1.68 \pm $0.69 \%)$. Fat content of the subsamples obtained by mixing full-fat and naturally creamed milk $(S+$ fat standardization and Grana Padano treatment) was $2.74 \%$. Protein content presented similar means across experimental treatments being $3.41 \pm 0.18 \%$ in the case of full-fat milks and, as expected, were slightly higher for fat standardized and naturally creamed subsamples due to the removal of fat. Casein also differed very little across treatments, except in the natural creaming and fat standardized subsamples where, for the same 
Table 2. Quality traits of milk samples in the 10 experimental conditions obtained by modifying individually and all together the lactodynamographic testing conditions from the standard procedure to those specific to Grana Padano cheese (averages and SD)

\begin{tabular}{|c|c|c|c|c|c|c|c|}
\hline Experimental treatment & $\begin{array}{c}\text { Fat, } \\
\%\end{array}$ & $\begin{array}{l}\text { CP, } \\
\%\end{array}$ & $\begin{array}{c}\text { Casein, } \\
\%\end{array}$ & Fat:Casein & $\begin{array}{c}\text { TS, } \\
\%\end{array}$ & $\mathrm{SCS}^{1}$ & $\mathrm{pH}^{2}$ \\
\hline Standard (S) & $3.79 \pm 1.03$ & $3.41 \pm 0.18$ & $2.76 \pm 0.14$ & $1.38 \pm 0.37$ & $12.81 \pm 0.93$ & $1.43 \pm 1.32$ & $6.51 \pm 0.08$ \\
\hline $\mathrm{S}+$ low temperature & $3.79 \pm 1.03$ & $3.41 \pm 0.18$ & $2.77 \pm 0.14$ & $1.37 \pm 0.37$ & $12.81 \pm 0.92$ & $1.64 \pm 1.31$ & $6.52 \pm 0.08$ \\
\hline $\mathrm{S}+$ acidification & $3.76 \pm 1.00$ & $3.40 \pm 0.18$ & $2.80 \pm 0.14$ & $1.35 \pm 0.36$ & $12.77 \pm 0.90$ & $1.50 \pm 1.27$ & $6.38 \pm 0.01$ \\
\hline $\mathrm{S}+$ lysozyme & $3.79 \pm 1.02$ & $3.41 \pm 0.18$ & $2.75 \pm 0.14$ & $1.38 \pm 0.37$ & $12.80 \pm 0.91$ & $1.37 \pm 1.58$ & $6.49 \pm 0.06$ \\
\hline Grana Padano & $2.74 \pm 0.37$ & $3.43 \pm 0.19$ & $2.85 \pm 0.15$ & $0.96 \pm 0.13$ & $11.93 \pm 0.40$ & $1.19 \pm 1.03$ & $6.38 \pm 0.03$ \\
\hline Simplified Grana Padano ${ }^{3}$ & $3.77 \pm 1.00$ & $3.41 \pm 0.18$ & $2.79 \pm 0.14$ & $1.35 \pm 0.36$ & $12.78 \pm 0.91$ & $1.54 \pm 1.10$ & $6.38 \pm 0.02$ \\
\hline
\end{tabular}

${ }^{1} \mathrm{SCS}=3+\log _{2}(\mathrm{SCC} / 100,000)$.

${ }^{2}$ Milk pH was measured at $35^{\circ} \mathrm{C}$.

${ }^{3} \mathrm{~A}$ simplified procedure circumventing creaming and mixing of creamed and full-fat milk, the most time consuming laboratory operations.

aforementioned reason, it was slightly higher (2.88 vs. $2.76 \%)$. Fat-to-casein ratio was, on average, $1.38 \pm 0.37$ for full-fat subsamples. This ratio was lower in naturally creamed $(0.58 \pm 0.23)$ and fat-standardized subsamples $(0.98 \pm 0.13)$ and in the Grana Padano procedure (0.96 \pm 0.12 ); in the last 2 conditions the fat-to-casein ratio was not equal to 1.00 and the standard deviation was not 0.00 , as they contained full-fat milk samples with a fat-to-casein ratio below 1.00 (these samples were analyzed as they were, without fat standardization). Total solids were about $12.81 \pm 0.93 \%$ in full-fat milk subsamples and were obviously lower in partially skimmed subsamples.

The SCS differed considerably across experimental treatments; values for full-fat subsamples were 1.37 to 1.64 (corresponding to 32,000 to 39,000 on a linear retransformed scale; SCC $/ \mathrm{mL}$ ), whereas naturally creamed subsamples were, on average, $76 \%$ lower ( -0.61 , corresponding to $8,200 \mathrm{SCC} / \mathrm{mL})$. The $\mathrm{S}+$ fat standardization and Grana Padano subsamples had SCS of 1.01 and 1.19, corresponding to a linear decrease of SCC equal to 29 and $19 \%$, respectively. Milk pH was similar (6.49 to 6.52) in all untreated subsamples, whereas it was 6.38 in the case of acidified subsamples (S + Acidification, Grana Padano, and simplified Grana Padano treatments).

\section{ANOVA}

Descriptive statistics and ANOVA of traditional MCP and of $\mathrm{CF}_{t}$ modeling equation parameters obtained with the different lactodynamographic testing conditions are summarized in Table 3. Of the fixed effects included in the statistical model, treatment and pendulum were highly significant $(P<0.001)$ for all traits considered, whereas instrument affected only $\mathrm{k}_{20}, \mathrm{CF}_{\mathrm{P}}(P<0.01)$, and $\mathrm{k}_{\mathrm{CF}}(P<0.05)$ and session was never significant.
Of the random effects, animal exhibited greater variability compared with what found for subsample within animal (about half of animal variability) and for replicates within subsamples (Table 3). The heteroskedastic residual variances assessed by Levene's test indicated that experimental procedures affected repeatability of all traits considered with the exception of the latest ones $\left(\mathrm{a}_{60}\right.$ for traditional MCP and $\mathrm{CF}_{\mathrm{P}}$ for model parameters). The RCT and $\mathrm{a}_{30}$ remained heteroskedastic in after log-transformation (Table 3 ).

\section{Comparison of Experimental Treatments Versus Standard Procedure}

Least squares means of traditional MCP and of $\mathrm{CF}_{t}$ modeling equation parameters in the 10 experimental treatments are summarized in Table 4. Compared with the standard procedure, gelation was delayed and $\mathrm{RCT}$ and $\mathrm{RCT}_{\text {eq }}$ were longer with natural creaming, fat standardization, and especially with reduction in the cheesemaking temperature, whereas it was earlier in rennet $5 \%$ pepsin, acidification of milk sample, and especially with doubling of the rennet concentration. Combining the various favorable and unfavorable modifications to cheese making, the Grana Padano and simplified Grana Padano procedures showed slightly earlier gelation times compared with the standard procedure.

As shown by the longer $\mathrm{k}_{20}$ and smaller $\mathrm{k}_{\mathrm{CF}}$, the $\mathrm{CF}$ process was consistently slower with natural creaming and fat standardization (significant only with the model parameter), and much more so with reduction in coagulation temperature. The opposite effect was exerted by milk acidification, rennet with $5 \%$ pepsin, and especially by doubling the rennet concentration (Table 4). Combining the different variations resulted in a nonsignificant modification of the traditional MCP $\left(\mathrm{k}_{20}\right)$ and a reduction in the model parameter $\left(\mathrm{k}_{\mathrm{CF}}\right)$ in 
Table 3. Descriptive statistics and analyses of variance of traditional milk coagulation properties (single point traits) and of curd firming modeling ( $\mathrm{CF}_{\mathrm{t}}$ ) equation parameters (using all 240 point observations per replicated sample) obtained in the different lactodynamographic testing conditions (600 lactodynamographic tests)

\begin{tabular}{|c|c|c|c|c|c|c|c|c|c|}
\hline \multirow[b]{2}{*}{ Item } & \multirow[b]{2}{*}{$\mathrm{df}$} & \multicolumn{5}{|c|}{ Traditional coagulation properties ${ }^{1}$} & \multicolumn{3}{|c|}{$\mathrm{CF}_{\mathrm{t}}$ equation parameters ${ }^{2}$} \\
\hline & & $\begin{array}{c}\mathrm{RCT}, \\
\min \end{array}$ & $\begin{array}{l}\mathrm{k}_{20}, \\
\min \end{array}$ & $\begin{array}{l}\mathrm{a}_{30}, \\
\mathrm{~mm}\end{array}$ & $\begin{array}{l}\mathrm{a}_{45}, \\
\mathrm{~mm}\end{array}$ & $\begin{array}{l}\mathrm{a}_{60}, \\
\mathrm{~mm}\end{array}$ & $\begin{array}{l}\mathrm{RCT}_{\text {eq }} \\
\min \end{array}$ & $\begin{array}{l}\mathrm{CF}_{\mathrm{P}}, \\
\mathrm{mm}\end{array}$ & $\begin{array}{c}\mathrm{k}_{\mathrm{CF}}, \\
\% \min ^{-1}\end{array}$ \\
\hline Average & - & 15.7 & 3.4 & 46.7 & 57.8 & 61.3 & 16.1 & 62.1 & 11.5 \\
\hline SD & - & 6.0 & 1.3 & 15.5 & 9.8 & 7.5 & 5.9 & 6.0 & 3.2 \\
\hline \multicolumn{10}{|l|}{ Fixed effects ( $F$-value $)$} \\
\hline Session & 3 & 0.5 & 0.8 & 0.7 & 1.0 & 1.1 & 0.5 & 1.2 & 0.6 \\
\hline Testing conditions & 9 & $55.1 * * *$ & $22.4^{* * *}$ & $33.9^{* * *}$ & $12.5^{* * *}$ & $6.9^{* * *}$ & $54.9^{* * *}$ & $5.8^{* * *}$ & $83.3^{* * *}$ \\
\hline Instrument & 1 & 0.0 & $6.8^{* *}$ & 0.1 & 0.3 & 3.8 & 0.1 & $10.3^{* *}$ & $29.7 * * *$ \\
\hline Pendulum (instrument) & 14 & $12.9^{* * *}$ & $35.1^{* * *}$ & $25.9^{* * *}$ & $47.7^{* * *}$ & $55.7^{* * *}$ & $14.6^{* * *}$ & $19.3^{* * *}$ & $28.7^{* * *}$ \\
\hline \multicolumn{10}{|l|}{ Random effects (SD) } \\
\hline Animal (within date) & 11 & 4.96 & 1.09 & 13.1 & 7.8 & 5.3 & 4.85 & 3.7 & 2.52 \\
\hline Subsample (within animal) & 263 & 2.32 & 0.54 & 6.1 & 4.5 & 3.5 & 2.29 & 2.7 & 1.00 \\
\hline Replicate (within subsample) & 298 & 0.84 & 0.33 & 2.8 & 2.2 & 2.1 & 0.84 & 2.0 & 0.64 \\
\hline Heteroskedasticity $^{3}$ ( $F$-value) & - & $6.2^{* * *}$ & $2.0^{*}$ & $4.2^{* * *}$ & $2.5^{* *}$ & 1.6 & $6.3^{* * *}$ & 1.7 & $2.8^{* *}$ \\
\hline Heteroskedasticity $\operatorname{Ln}^{4}(F$-value $)$ & - & $5.3^{* * *}$ & 1.3 & $2.5^{* *}$ & 1.8 & 1.6 & $6.5^{* * *}$ & 1.9 & 1.4 \\
\hline
\end{tabular}

$\overline{{ }^{1} \mathrm{RCT}}=$ measured rennet gelation time; $\mathrm{k}_{20}=$ time interval between gelation and attainment of curd firmness of $20 \mathrm{~mm} ; \mathrm{a}_{30}\left(\mathrm{a}_{45}, \mathrm{a}_{60}\right)=$ curd firmness after $30(45,60) \mathrm{min}$ from rennet addition.

${ }^{2} \mathrm{RCT}_{\mathrm{eq}}=\mathrm{RCT}$ estimated according to the $\mathrm{CF}_{\mathrm{t}}$ model; $\mathrm{CF}_{\mathrm{P}}=$ asymptotic potential curd firmness; $\mathrm{k}_{\mathrm{CF}}=$ curd firming instant rate constant.

${ }^{3}$ Heteroskedasticity (Levene's test) refers to the effect of condition on residual variance.

${ }^{4}$ Data were $\log$-transformed before testing for heteroskedasticity.

$* P<0.05 ;{ }^{* *} P<0.01 ;{ }^{* * *} P<0.001$ 
Table 4. Least squares means of traditional milk coagulation properties (single-point traits) and of curd firming modeling equation parameters (using all 240 point observations per replicated sample) obtained in the different lactodynamographic testing conditions (asterisks refer to the significance of the contrast of the tested condition vs. standard conditions)

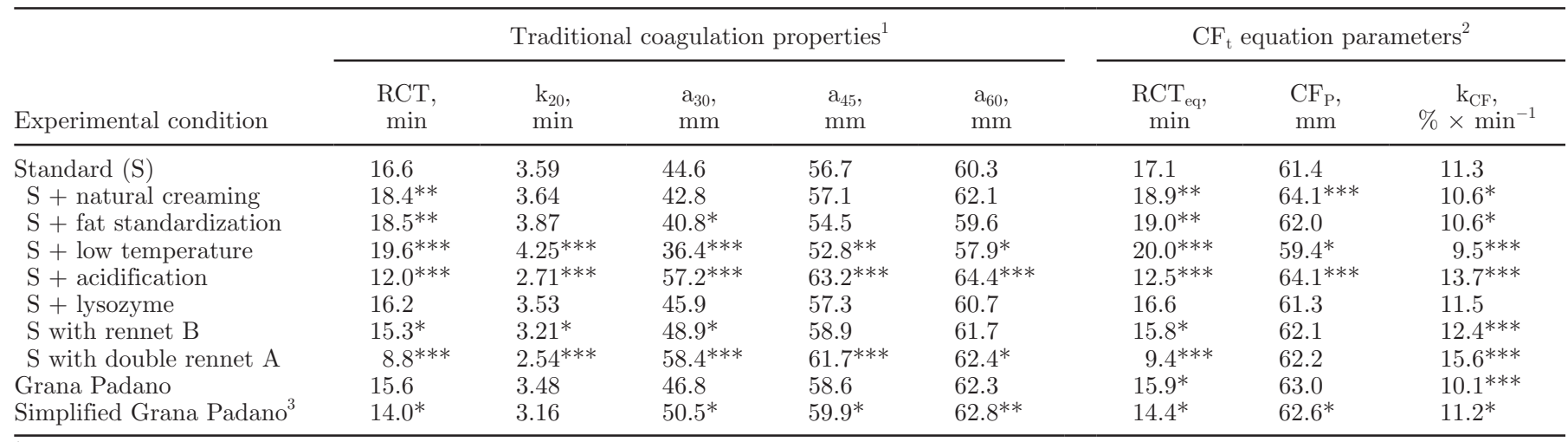

${ }^{1} \mathrm{RCT}=$ measured rennet gelation time; $\mathrm{k}_{20}=$ time interval between gelation and attainment of curd firmness of $20 \mathrm{~mm} ; \mathrm{a}_{30}\left(\mathrm{a}_{45}, \mathrm{a}_{60}\right)=\mathrm{curd}$ firmness at $30(45,60)$ min after rennet addition.

${ }^{2} \mathrm{RCT}_{\mathrm{eq}}=\mathrm{RCT}$ estimated according to curd firm change over time modeling $\left(\mathrm{CF}_{\mathrm{t}}\right) ; \mathrm{CF}_{\mathrm{P}}=$ asymptotic potential curd firmness; $\mathrm{k}_{\mathrm{CF}}=$ curd firming instant rate constant.

${ }^{3} \mathrm{~A}$ simplified procedure circumventing creaming and mixing of creamed and full-fat milk, the most time consuming laboratory operations.

${ }^{*} P<0.05$; ** $P<0.01$; *** $P<0.001$.

both the complete and simplified Grana Padano procedures with respect to the standard one.

Curd firmness measured $30\left(\mathrm{a}_{30}\right), 45\left(\mathrm{a}_{45}\right)$, and 60 $\left(\mathrm{a}_{60}\right)$ min after rennet addition according to traditional $\mathrm{MCP}$ or predicted at infinite time $\left(\mathrm{CF}_{\mathrm{P}}\right)$ on the basis of $\mathrm{CF}_{t}$ modeling, yielded different results (Table 4). In fact, the $\mathrm{CF}_{\mathrm{P}}$ parameter was slightly modified according to experimental treatment; it increased with natural creaming, acidification, and in the simplified Grana Padano procedure and decreased with the lowering of processing temperature respect to standard procedure. Conversely, the $\mathrm{a}_{30}$ decreased with fat standardization and was strongly affected by low temperature (causing a reduction) and by acidification, rennet with $5 \%$ pepsin, and doubling rennet (causing an increase). These differences respect to standard procedure progressively decreased moving to $\mathrm{a}_{45}$ and $\mathrm{a}_{60}$, showing that they are not an intrinsic property of the curd but are nonetheless strongly affected by gelation time and CF. As an effect of the trade-off between favorable and unfavorable factors, the Grana Padano procedure did not differ from the standard procedure, whereas absence of fat standardization in the simplified Grana Padano procedure tended to increase the CF traits (Table 4).

\section{Correlations Between Replicates (Repeatability) and Between Treatments (Predictability)}

Correlations within and between treatments of traditional MCP and $\mathrm{CF}_{t}$ modeling equation parameters are reported in Table 5. Correlations between replicates of each subsample within treatment were used as a mea- sure of repeatability. Comparing the analyzed traits, it is evident that repeatability is very high for the first trait measured (RCT, both as a single-point measure and as an equation parameter) and tends to decrease over time for the parameters measured or estimated using subsequent information until the smallest repeatability obtained for the asymptotic potential $\mathrm{CF}$ value $\left(\mathrm{CF}_{\mathrm{P}}\right)$.

The results of Levene's tests show repeatability of the method to be affected by procedure changes for all traits considered, with the exception of $\mathrm{a}_{60}$ and $\mathrm{CF}_{\mathrm{P}}$ (Table 3). Compared with the standard procedure, natural creaming and fat standardization tended to improve repeatability of the traits that were significant in Levene's test; low temperature and especially milk acidification decreased repeatability; and lysozyme, rennet with $5 \%$ pepsin, and double rennet had little effect on the repeatability of both traditional MCP and $\mathrm{CF}_{t}$ model parameters. The combination of the various modifications to the Grana Padano procedure led to a decrease in correlations between replicates (lower repeatability) for all significant traits in Levene's test. Absence of fat standardization in the simplified Grana Padano treatment tended to yield results intermediate between the 2 extreme conditions.

Correlations between the 2 extreme methods (standard vs. Grana Padano) when only 1 of the 2 replicates was considered were much lower than the within-condition correlations, especially in the case of the late traits $\left(\mathrm{a}_{60}\right.$ and $\left.\mathrm{CF}_{\mathrm{P}}\right)$. Using an average of the 2 replicates of each subsample only partially increased the correlations. Absence of fat standardization in the simplified 
Table 5. Correlations between replicates of subsamples within condition (as indicator of repeatability) and between extreme conditions (as indicator of predictability of one condition by another) of traditional milk coagulation properties (single point traits) and of curd firm change over time $\left(\mathrm{CF}_{\mathrm{t}}\right)$ modeling equation parameters (using all 240 point observations per replicated sample)

\begin{tabular}{|c|c|c|c|c|c|c|c|c|}
\hline Item & \multicolumn{5}{|c|}{ Traditional coagulation properties ${ }^{1}$} & \multicolumn{3}{|c|}{$\mathrm{CF}_{\mathrm{t}}$ equation parameters ${ }^{2}$} \\
\hline \multicolumn{9}{|l|}{ Within condition (repeatability) ${ }^{3}$} \\
\hline Standard $(\mathrm{S})$ & 0.98 & 0.86 & 0.95 & 0.88 & 0.75 & 0.98 & 0.55 & 0.94 \\
\hline $\mathrm{S}+$ natural creaming & 0.99 & 0.91 & 0.97 & 0.94 & 0.84 & 0.99 & 0.58 & 0.95 \\
\hline $\mathrm{S}+$ fat standardization & 0.99 & 0.92 & 0.95 & 0.93 & 0.84 & 0.99 & 0.42 & 0.90 \\
\hline $\mathrm{S}+$ lysozyme & 0.96 & 0.79 & 0.94 & 0.83 & 0.73 & 0.96 & 0.59 & 0.92 \\
\hline $\mathrm{S}$ with rennet $\mathrm{B}$ & 0.97 & 0.84 & 0.92 & 0.80 & 0.66 & 0.96 & 0.52 & 0.90 \\
\hline $\mathrm{S}$ with double rennet $\mathrm{A}$ & 0.99 & 0.86 & 0.87 & 0.75 & 0.71 & 0.99 & 0.69 & 0.94 \\
\hline Grana Padano & 0.93 & 0.68 & 0.90 & 0.73 & 0.61 & 0.93 & 0.57 & 0.87 \\
\hline Simplified Grana Padano ${ }^{3}$ & 0.97 & 0.73 & 0.90 & 0.76 & 0.64 & 0.97 & 0.65 & 0.78 \\
\hline \multicolumn{9}{|l|}{ Between conditions (first replicates) } \\
\hline Standard vs. Grana Padano & 0.67 & 0.52 & 0.69 & 0.53 & 0.33 & 0.67 & 0.18 & 0.64 \\
\hline \multicolumn{9}{|l|}{ Between conditions (replicate means) } \\
\hline
\end{tabular}

${ }^{1} \mathrm{RCT}=$ measured rennet gelation time; $\mathrm{k}_{20}=$ time interval between gelation and attainment of curd firmness of $20 \mathrm{~mm} ; \mathrm{a}_{30}\left(\mathrm{a}_{45}, \mathrm{a}_{60}\right)=$ curd firmness at $30(45,60)$ min after rennet addition.

${ }^{2} \mathrm{RCT}_{\mathrm{eq}}=\mathrm{RCT}$ estimated according to the $\mathrm{CF}_{\mathrm{t}}$ model; $\mathrm{CF}_{\mathrm{P}}=$ asymptotic potential curd firmness; $\mathrm{k}_{\mathrm{CF}}=$ curd firming instant rate constant.

${ }^{3} \mathrm{~A}$ simplified procedure circumventing creaming and mixing of creamed and full-fat milk, the most time consuming laboratory operations.

Grana Padano procedure also resulted in much lower correlations between the 2 conditions than between replicates, although they were greater than those between the standard and Grana Padano methods (Table 5).

\section{DISCUSSION}

\section{Milk Quality, Coagulation Traits, and Curd Firming Modeling}

Fat and protein contents of the milk samples used in the present study were similar to those in the milk of dual-purpose Simmental cows reared in Italy (fat $3.89 \%$, protein $3.42 \%$; AIA, 2013; i.e., greater than in Holstein milk and lower than in Brown Swiss). Holstein is the dominant breed in the area of production of Grana Padano, where interest is increasing for crossbreeding with other dairy breeds such as Simmental or Montbéliarde, Brown Swiss, and Scandinavian breeds (Malchiodi et al., 2014). However, Brown Swiss and Simmental or Montbéliarde breeds are prevalent in the Alps, where Trentingrana, a specification of Grana Padano, is produced (Sturaro et al., 2013). The somatic cells found (on average 1.43 SCS corresponding to about 33,600 cells $/ \mathrm{mL}$ of milk) also confirm the low fat and protein content characterizing this breed. The average RCT obtained in the present study using the standard procedure (16.6 $\mathrm{min}$ ) confirms that previously found $(16.5 \mathrm{~min})$ in a large survey by Bonfatti et al.
(2011) on the same breed but with a different instrument, whereas $\mathrm{a}_{30}$ was much higher (44.6 vs. $29.1 \mathrm{~mm}$, respectively). Using the same standard procedure and the same instrument as the present study, Malchiodi et al. (2014) compared milk from cows belonging to 7 breed combinations, including purebred Holsteins and Montbéliarde $\times$ Holstein crossbreds (Montbéliarde is genetically close to the dual-purpose Simmental breed). Their results conformed to expectations based on previous work. In fact, RCT was 21.4 and 19.7 versus 16.6 min, respectively, for purebred Holstein and Montbéliarde crosses versus the purebred Simmental of the present study, whereas $\mathrm{k}_{20}$ was 5.3 and 3.9 versus 3.6 min, and $\mathrm{a}_{30}$ was 30.4 and 38.6 versus $44.6 \mathrm{~mm}$, respectively. Both purebred Simmental and Montbéliarde cows are known to be superior to Holstein Friesian in these traits, although in their review Bittante et al. (2012) highlighted the great variability in average values found in the literature and the need for standardization of lactodynamographic techniques.

No published results are available for $\mathrm{CF}_{t}$ modeling of this breed. In a large survey on Brown Swiss cows, Bittante et al. (2015) prolonged the test duration to 90 min and observed in almost all samples a decrease in CF in the final part of the test due to syneresis and whey expulsion. In the present study, with a test duration of $60 \mathrm{~min}$, the decreasing phase was not evident in the majority of samples nor could the syneresis instant rate constant be estimated. Malchiodi et al. (2014) obtained 
the same result with Holstein purebreds and Montbéliarde $\times$ Holstein crossbreds with a test duration of 60 min. The equation parameter $\mathrm{RCT}_{\mathrm{eq}}$ estimated for each milk sample using all 240 point observations gave very similar results to single point RCT (22.4 and 19.2 vs. 17.1 min, respectively, with purebred Holsteins and Montbéliarde crossbreeds vs. the purebred Simmental cows in the present study). Conversely, the other 2 parameters estimated by the $\mathrm{CF}_{t}$ model yielded different patterns from those obtained with traditional MCP. In fact, in the previous study, the asymptotic $\mathrm{CF}_{\mathrm{P}}$ value was very similar for the 2 types of cows (49.6 and 50.9 $\mathrm{mm}$, respectively) and the $\mathrm{k}_{\mathrm{CF}}$ instant rate constant was better with the crossbreeds (12.1 and $\left.13.6 \% \times \mathrm{min}^{-1}\right)$, whereas in the present study the purebred Simmental yielded milk samples characterized by a greater $\mathrm{CF}_{\mathrm{P}}$ $(61.4 \mathrm{~mm})$ and a smaller $\mathrm{k}_{\mathrm{CF}}\left(11.3 \% \times \mathrm{min}^{-1}\right)$.

Regarding the source of variation in traditional MCP and $\mathrm{CF}_{t}$ model parameters, it is worth noting that the laboratory session was never significant and the instrument affected measurement of the firming rate $\left[k_{20}\right.$ and syneresis instant rate constant $\left.\left(\mathbf{k}_{\mathrm{SR}}\right)\right]$. Low reproducibility, together with low repeatability, was observed in an interlaboratory study carried out by a commission of the Italian Animal Science and Production Association (Caroli and Cauvin, 1999). Furthermore, the highly significant effect of pendula for all traits confirms published results (Ikonen et al. 2004; Tyrisevä et al., 2004; Pazzola et al., 2014), showing that, despite frequent calibration of each pendulum, this factor also needs to be taken into account in the statistical analyses.

Aside from the average values, it is worth noting that individual animal is the most important of the random sources of variation considered (Caroli et al., 1990; Tyrisevä et al., 2003), representing between 71 and $82 \%$ of total variance for all traits (based on data in Table 3), with the exception of those recorded during the last phase of measurement $\left(71,63\right.$, and $55 \%$ for $\mathrm{a}_{45}$, $\mathrm{a}_{60}$, and $\mathrm{CF}_{\mathrm{P}}$, respectively). Subsample within animal represented 13 to $18 \%$ of total variance for the first group of traits and 24 to $29 \%$ for the second group. Residual variance (between replicates) also varied from 2 to $7 \%$ for the first group of traits and from 6 to $16 \%$ for the second. Similar values were found by Caroli et al. (1990) for traditional MCP. It can be noted from Table 5 that repeatability is very good for the first traits obtained ( $\mathrm{RCT}$ and $\mathrm{RCT}_{\mathrm{eq}}$ ) and tends to decrease over time to reach the lowest values for $\mathrm{a}_{60}$ and $\mathrm{CF}_{\mathrm{P}}$. This phenomenon is explained by the fact that variations affecting the $\mathrm{CF}$ during the test tend to accumulate with time. It should be taken into account that these last traits are important to industry, as they have the highest correlation with variation in cheese yield and especially in milk fat and protein recovery in the curd (A. Cecchinato and G. Bittante, unpublished data).

The lower repeatability of these last traits compared with those measured during the first stage of the lactodynamographic test is evident when it is expressed in relative terms through correlation coefficients (Table 5 ), but it is not the case if expressed in terms of absolute residual variations between replicates. The data in Table 3 clearly show that with respect to the CF traits measured in millimeters, the residual standard deviation between replicates tends to decrease from the earlier to the later traits $\left(\mathrm{a}_{30}, \mathrm{a}_{45}, \mathrm{a}_{60}\right.$, to $\left.\mathrm{CF}_{\mathrm{P}}\right)$ rather than increase. Another indirect measure of instrumental repeatability is the coefficient of variation $(\mathbf{C V})$ obtained from Table 3 expressing the residual SD between replicates as a percentage of the mean value of the trait. The 2 gelation times were characterized by similar $\mathrm{CV}$ (5.4 and $5.2 \%$ for $\mathrm{RCT}$ and $\mathrm{RCT}_{\text {eq }}$, respectively). The model measure of curd firming velocity was characterized by a much smaller residual CV than the traditional trait $\left(\mathrm{k}_{\mathrm{CF}}=5.6 \% \mathrm{vs}_{20}=9.7 \%\right)$. Lastly, the $\mathrm{CF}$ measures had a residual CV decreasing from $6.6 \%$ for $\mathrm{a}_{30}$ to $3.2 \%$ for $\mathrm{CF}_{\mathrm{P}}$. The decreasing values in the correlation coefficients between replicates of the later traits is due to lower phenotypic variability leading to a reduction in the variance explained by the cause of variation included in the model and not to an increase in residual variance.

The variations tested in the analytical procedure not only had significant effects on the average values of all the traits considered, but also brought about a change in the residual variability (differences between pairs of replicates); that is, they affected the instrumental repeatability of the measures of all traits with the exception of the last $2\left(\mathrm{a}_{60}\right.$ and $\left.\mathrm{CF}_{\mathrm{P}}\right)$, as shown by the significances of Levene's test (Table 3). Published papers dealing with the effects of different technical factors on MCP generally report and discuss the effects on means, but not on residual variability.

\section{Natural Creaming and Fat Standardization}

Natural creaming is an important step in the Grana Padano PDO and many other hard cheesemaking processes, not only to obtain the desired fat-to-casein ratio in milk and cheese, but also to remove antidairy bacteria (Bottazzi, 1976; Bertoni et al., 2001; Feligni et al., 2014). A study conducted by Pecorari (1994) on Parmigiano-Reggiano cheese showed that 10 to 12 $\mathrm{h}$ of natural creaming removed more than half the fat initially present in the milk and decreased SCS and Clostridium spores by about 90\%. Caplan et al. (2013) observed an effect of time and temperature on gravity 
separation of fat, SCC, and bacteria, and Geer and Barbano (2014) demonstrated that aggregation and gravity separation are affected by the interaction between SCC and immunoglobulin. The laboratory procedure used in the present study to mimic hard cheese production using natural creaming attained the objective of removing more than half the fat of full-fat milk (56\%). Indirect confirmation of the ability of natural creaming to debacterialize milk comes from the change in SCC. The variation in average SCS from 1.43 to -0.61 means a variation of retransformed SCC averages between 33,680 and 8,190 cells $/ \mathrm{mL}$ (i.e., $-76 \%$, even where the initial SCC value was very small).

Milk quality traits for fat standardized milk derive from blending partially skimmed and full-fat milk. Fat-to-casein ratio $(0.98 \pm 0.13)$ was in accordance with production specifications for Grana Padano PDO cheese and is usually obtained in practice by natural creaming of milk taken from 2 consecutive milkings until the desired fat-to-casein ratio is reached, or by blending creamed milk from the previous evening with full-fat milk from the subsequent morning milking shortly before commencing cheese making. This last method is mandatory for Parmigiano-Reggiano and Trentingrana Italian hard cheeses and was preferred in the laboratory. In the present study, the proportions of creamed and full-fat milks in blends varied according to their fat-to-casein ratios to obtain a final value of 1.00; they were, on average, not very different from 1:1. Table 2 clearly shows that the fat-standardized milk had a chemical composition intermediate between the full-fat and the creamed samples. The SCC were, on average, $25 \%$ lower than in full-fat milk

Compared with the initial full-fat milk, fat-to-caseinstandardized milk showed longer RCT, but an improvement in the curd firming rate (ZanNoni and Nanni,1982) and an increase in curd firmness (Tedeschi et al., 1993). In terms of traditional $\mathrm{MCP}$ and $\mathrm{CF}_{t}$ modeling, the significant differences between the standard procedure and both the creamed $\left(\mathrm{RCT}, \mathrm{RCT}_{\mathrm{eq}}, \mathrm{CF}_{\mathrm{P}}\right.$, and $\mathrm{k}_{\mathrm{CF}}$ ) and fat-standardized samples $\left(\mathrm{RCT}, \mathrm{a}_{30}, \mathrm{RCT}_{\mathrm{eq}}\right.$, and $\mathrm{k}_{\mathrm{CF}}$ ) had a modest fixed effect on the overall curd firming pattern, as shown in Figure 1. This result confirms the low correlations between milk fat content and MCP at both the phenotypic and genetic levels found in several studies (Ikonen et al., 2004; Cecchinato et al., 2011; Cipolat-Gotet et al., 2012). Fat content can affect repeatability of the lactodynamographic test, as shown by the tendency toward greater repeatability resulting from natural creaming and fat standardization (Table 5). Moreover, to avoid possible interactions with other nutrients and increase repeatability, some researchers have analyzed coagulation properties of milk samples

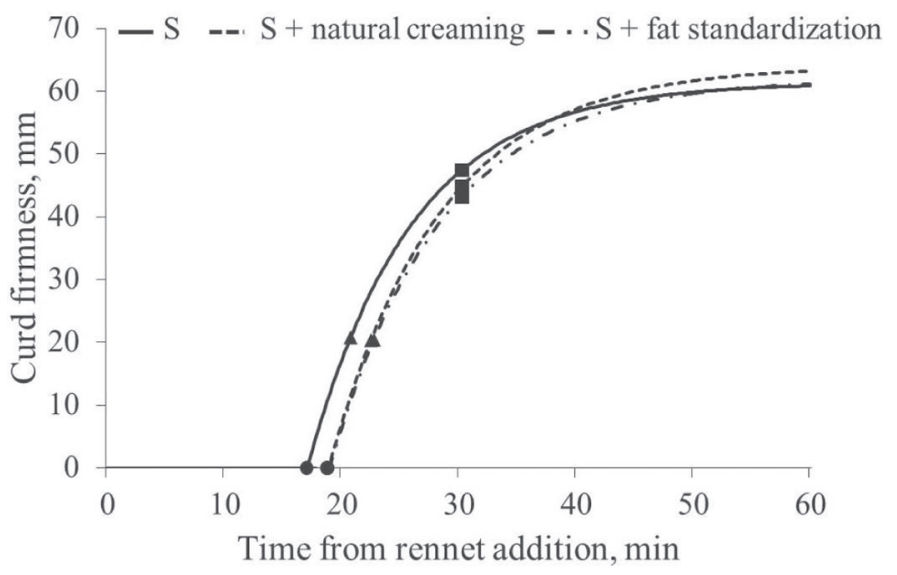

Figure 1. Pattern of curd firmness after rennet addition according to curd firm change over time $\left(\mathrm{CF}_{\mathrm{t}}\right)$ modeling of milk samples tested according to the standard procedure (S), S + natural creaming, and $\mathrm{S}+$ fat standardization to about 1:1 fat:casein ratio; traditional coagulation properties are also reported $($ circles $=$ rennet coagulation time, triangles $=$ time interval between gelation and attainment of curd firmness of $20 \mathrm{~mm}$, and squares $=$ curd firmness at 30 min after rennet addition).

that have been totally skimmed by centrifuging (Hallen et al., 2007; Klandar et al., 2007; Jensen et al., 2012).

\section{Cheesemaking Temperature Reduction}

It is well known that coagulation progresses more rapidly with increasing temperature and because of an effect on milk pH (Lagoueyte et al., 1994; Mishra et al., 2005; Castillo et al., 2006), thus the large negative effects on all MCP obtained by reducing vat temperature from 35 to $32^{\circ} \mathrm{C}$ were expected. What was not well known was the pattern obtained by data modeling, shown in Figure 2, which makes it clear that this modification of the standard procedure has a much greater effect on the curd firming process than creaming and fat standardization (Malacarne et al., 2008). Something else that was not well known was the effect of temperature on repeatability of the coagulation traits, which tended to worsen for the early recorded traits and to improve for the late recorded $\mathrm{MCP}$ traits and $\mathrm{CF}_{t}$ modeling parameters (Table 5).

\section{Milk Acidification}

The importance of $\mathrm{pH}$ for cheesemaking is well known. Acidity, expressed as $\mathrm{pH}$ or titratable acidity, is the milk trait most highly correlated, both genetically and phenotypically, with traditional MCP (Bittante et al., 2012). Milk acidity is often increased in the cheesemaking process through the addition of a microbial starter culture or, especially for PDO cheeses, by add- 


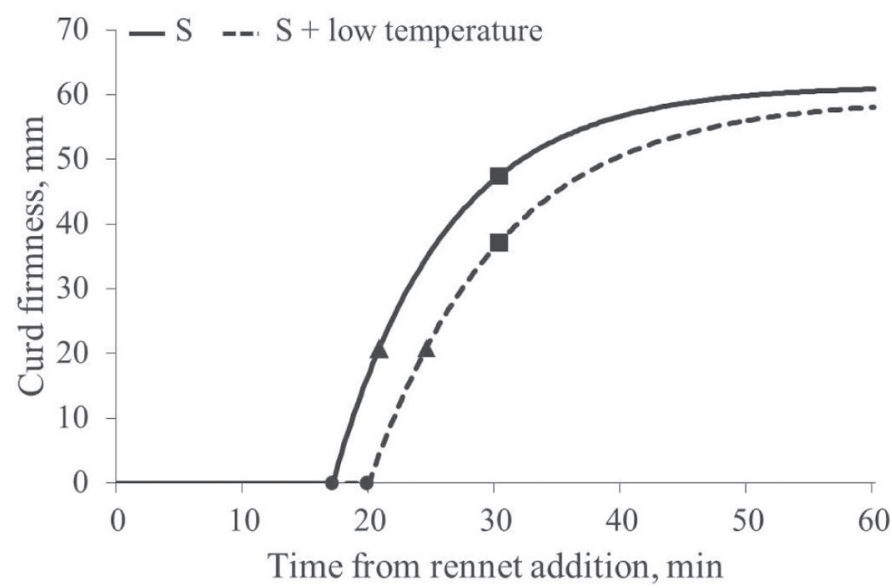

Figure 2. Pattern of curd firmness after rennet addition according to curd firm change over time $\left(\mathrm{CF}_{\mathrm{t}}\right)$ modeling of milk samples tested according to the standard procedure $(\mathrm{S})$, and with reduction of cheese-making temperature from 35 to $32^{\circ} \mathrm{C}$ ( $\mathrm{S}+$ low temperature); traditional coagulation properties are also reported $($ circles $=$ rennet coagulation time, triangles $=$ time interval between gelation and attainment of curd firmness of $20 \mathrm{~mm}$, and squares $=$ curd firmness at $30 \mathrm{~min}$ after rennet addition).

ing native microflora as cultured milk or, as in the case of Grana Padano, cultured whey (Castillo et al., 2006). The improvement in MCP average values, and especially RCT, caused by milk acidification (Table 4) fully confirms the results obtained in earlier studies (Okigbo et al., 1985; Mishra et al., 2005). Modeling $\mathrm{CF}_{t}$ data allows the strong effect of $\mathrm{pH}$ standardization on the coagulation processes (Figure 3) to be fully appreciated. Conversely, the adverse effect of this operation on the repeatability of the lactodynamographic test, which has not been previously studied, should be recognized. According to Macheboeuf et al. (1993), standardization of $\mathrm{pH}$ of native milk samples to a constant level reduced variability in all traditional MCP among samples from different animals, but did not affect the differences brought about by other causes, such as genetic variants of casein fractions.

\section{Lysozyme Addition}

Lysozyme (hen egg enzyme) is allowed by the Grana Padano PDO production specifications to be added to the milk up to a maximum of $2.5 \mathrm{~g} / 100 \mathrm{~kg}$ of milk, as it prevents and controls Clostridium growth during cheese ripening (Cunningham et al., 1991; Bottazzi et al., 1993; Pecorari et al., 2003) given that this and other PDO cheeses should be made from raw milk without any thermal treatment. Lysozyme addition did not modify milk chemical composition nor traditional $\mathrm{MCP}$ or $\mathrm{CF}_{t}$ modeling, as shown in Figure 4, and was found to make little difference to milk $\mathrm{pH}$ (6.49 vs.
6.51). Lysozyme may not be added to other similar long-ripened hard PDO cheeses (Parmigiano-Reggiano and Trentingrana), although production specifications prohibit the use of silages and discourage the use of pasture, these being the main practices responsible for increased clostridia in milk (Julien et al., 2008). Lysozyme also exerted a very small effect on repeatability of the lactodynamographic test (Table 5).

\section{Type and Quantity of Rennet}

Rennet activity is the core of the cheesemaking process and has been widely studied (McMahon and Brown, 1982; Nájera et al., 2003). It is well known that RCT tend to halve when rennet activity is doubled (Okigbo et al., 1985), as happened in the present study. However, the increase in rennet activity also accelerated the $\mathrm{CF}$ process, as shown by the decrease in $\mathrm{k}_{20}$ and the increase in $\mathrm{a}_{30}, \mathrm{a}_{45}$, and $\mathrm{k}_{\mathrm{SR}}$. It is worth noting that the quantity of rennet has no effect on long-term $\mathrm{CF}$, as represented by $\mathrm{CF}_{\mathrm{P}}$ and $\mathrm{a}_{60}$. This phenomenon is clearly shown in Figure 5. Accelerated coagulation obtained by increasing the rennet dose has been used by some researchers to avoid the problem of noncoagulating samples (Vallas et al., 2010), whose presence can misrepresent the coagulation pattern and bias statistical analyses (Ikonen et al., 1999; Cecchinato et al., 2011). This practice increases the distance between the lactodynamographic laboratory procedure and the dairy industry standard, also because an excess of pepsin can give ripened cheeses a bitter taste (Sousa et al., 2001). Another difference between industry and

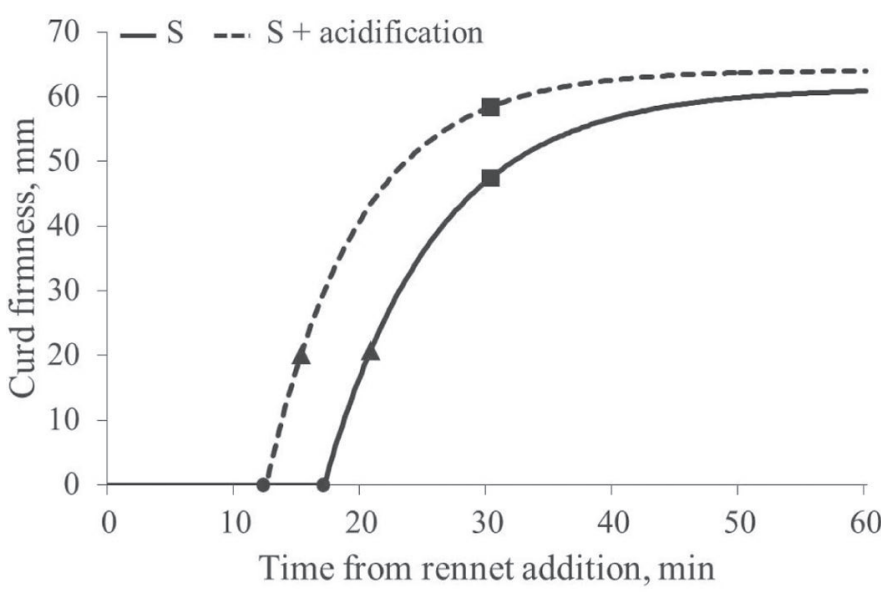

Figure 3. Pattern of curd firmness after rennet addition according to curd firm change over time $\left(\mathrm{CF}_{\mathrm{t}}\right)$ modeling of milk samples tested according to the standard procedure (S), and with reduction of milk $\mathrm{pH}$ to $6.38(\mathrm{~S}+$ acidification); traditional coagulation properties are also reported (circles $=$ rennet coagulation time, triangles $=$ time interval between gelation and attainment of curd firmness of $20 \mathrm{~mm}$, and squares $=$ curd firmness at $30 \mathrm{~min}$ after rennet addition). 


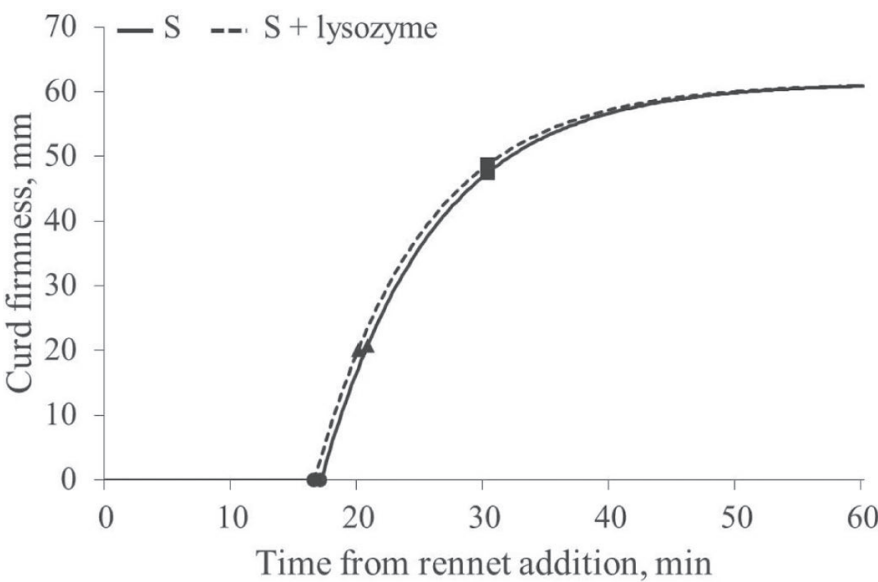

Figure 4. Pattern of curd firmness after rennet addition according to curd firm change over time $\left(\mathrm{CF}_{\mathrm{t}}\right)$ modeling of milk samples tested according to the standard procedure $(\mathrm{S})$, and $\mathrm{S}+$ lysozyme traditional coagulation properties are also reported (circles $=$ rennet coagulation time, triangles $=$ time interval between gelation and attainment of curd firmness of $20 \mathrm{~mm}$, and squares = curd firmness at 30 min after rennet addition).

laboratory conditions is the practice of standardizing the ratio between the rennet and casein content of vat milk. This is difficult to implement in the laboratory when a large number of samples need to be analyzed, but does not seem to be very important, given that protein content has very low phenotypic and genetic correlations with RCT and a moderate positive correlation with $\mathrm{a}_{30}$ (Bittante et al., 2012; Chessa et al., 2014).

The type of rennet can also play an important role. Production specifications for PDO Grana Padano and Parmigiano-Reggiano require the use of natural calf rennet with a low pepsin content (to avoid the risk of obtaining a bitter off-flavor during ripening). It is clear from the results of the present study that, even with the same theoretical IMCU activity, the 2 rennet preparations could give rise to different traits (Table 4), although this variation in the procedure has a minor effect on the pattern of coagulation and CF compared with the effect of rennet quantity (Figure 5). Whereas the type and quantity of rennet can have a large effect on average MCP and model parameters, the effect on repeatability of measures appears to be much lower (Table 5).

\section{Combining all Variations in the Grana Padano Procedure}

Milk quality traits for Grana Padano samples reflected those for $\mathrm{S}+$ fat standardization, whereas simplified Grana Padano reflected standard samples, except for $\mathrm{pH}$, as expected. In the Grana Padano procedure, the use of fat standardized milk set the fat-to-casein ratio to about $1(0.96 \pm 0.13)$, in accordance with the PDO production specification (between 0.80 and 1.05), whereas it was 1.35 for simplified Grana Padano. As expected, the SCS was lower in the Grana Padano than in the simplified Grana Padano samples (1.19 vs. 1.54, respectively, equal to a reduction of $22 \%$ on a linear scale).

The average CF patterns obtained with standard, Grana Padano, and simplified Grana Padano procedures are plotted in Figure 6. No appreciable differences were noticed between Grana Padano and standard patterns, meaning that favorable (acidification and rennet with $5 \%$ pepsin) and unfavorable (fat standardization and lower temperature) variations tended on average to compensate each other. No information is available in the literature regarding adaptation of the lactodynamographic test to the technological conditions typical of long-ripening hard PDO cheeses, although MCP obtained with standard or similar conditions are often adopted by the dairy industry to assess the suitability of milk for cheesemaking and also for the milk payment system (Bittante et al., 2011a,b). On the other hand, the simplified Grana Padano subsamples coagulated slightly faster than the other 2 treatments and tended to reach slightly greater $\mathrm{CF}$ values toward the end of the test (Figure 6). The 2 Grana Padano procedures had lower repeatability than the standard procedure, which seems to be due to the effect of low temperature and acidification. Again, no information is available in the literature.

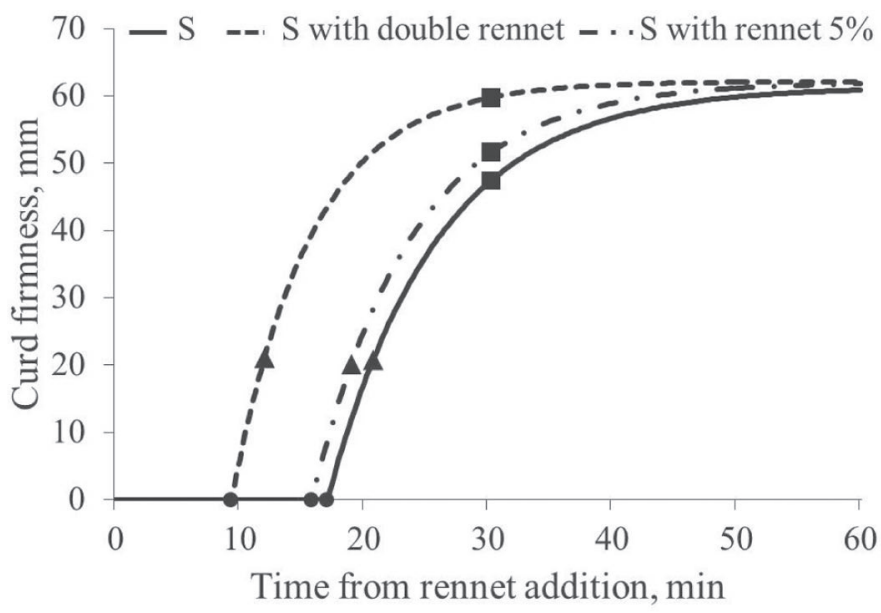

Figure 5. Pattern of curd firmness after rennet addition according to curd firm change over time $\left(\mathrm{CF}_{\mathrm{t}}\right)$ modeling of milk samples tested according to the standard procedure (S), with doubling of the rennet dose ( $\mathrm{S}$ with double rennet) and with substitution of rennet $20 \%$ pepsin with rennet $5 \%$ pepsin (S with rennet $5 \%$ ); traditional coagulation properties are also reported (circles $=$ rennet coagulation time, triangles $=$ time interval between gelation and attainment of curd firmness of $20 \mathrm{~mm}$, and squares $=$ curd firmness at $30 \mathrm{~min}$ after rennet addition). 


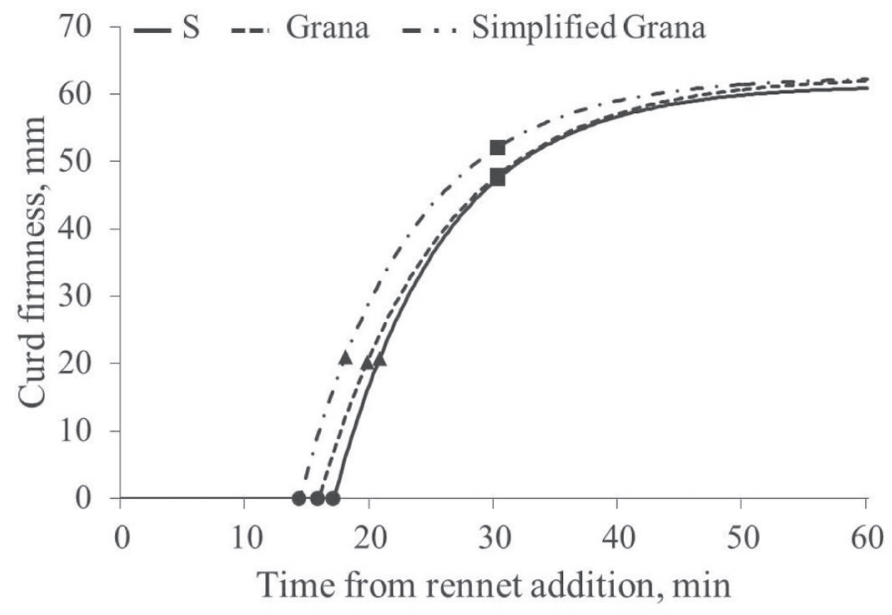

Figure 6. Effects of Grana Padano and simplified Grana Padano conditions compared with the standard condition (S) on curd firming modeling (equations) and traditional coagulation properties (circles $=$ rennet coagulation time, triangles $=$ time interval between gelation and attainment of curd firmness of $20 \mathrm{~mm}$, and squares = curd firmness at 30 min after rennet addition).

\section{Predictability of Milk Aptitude for Long-Ripened Hard Cheesemaking}

The standard procedure is almost equal to the Grana Padano procedure in terms of average $\mathrm{MCP}$ and $\mathrm{CF}_{t}$ parameters and pattern, and is much better in terms of repeatability, simplicity, and labor requirements. When assessing the ability of the standard procedure to mimic results obtained in the production of long-ripened hard PDO cheeses, however, correlations between procedures of individual milk samples should also be taken into account.

The results of correlation analyses between the 2 procedures for the traits considered revealed the standard method to have medium-to-good predictability (61 to $74 \%$ ), with the exception of the traits recorded in the last phase of the test $\left(\mathrm{a}_{60}\right.$ and $\left.\mathrm{CF}_{\mathrm{P}}\right)$ that showed the Grana Padano conditions to have lower predictability (41 and 24\%, respectively). The results obtained for different traits are clearly related to the repeatability of their measurement. To allow direct comparison with between-replicate correlations, the correlations between procedures using only one replicate and not their averages are also reported (Table 5). As is clear from the experimental results, the differences between the correlations obtained using only one replicate or the average of both increase with decreasing repeatability of the trait, but the difference between the between- and within-treatment correlations remained large, indicating that the fair predictability of the Grana Padano conditions is not due to repeatability problems but to individual milk samples reacting differently to different cheesemaking conditions (interactions between procedure and sample).

The simplified Grana Padano procedure was only slightly better than the standard procedure in predicting Grana Padano conditions, indicating that fat standardization probably plays an important role in the observed interaction between procedures. It seems evident that the complex procedures aiming at mimic a hard cheesemaking technology can be easily adopted for research purposes, but hardly could be adopted by industry for monitoring the production chain. A simplified approach could be developed using Fourier-transform infrared (FTIR) spectrometry. This secondary methodology yielded acceptable results for predicting the traits obtained with standard lactodynamography, especially for monitoring or genetic purposes (Cecchinato et al., 2009), and the validation results can be improved if innovative approaches are used for calibration (Ferragina et al., 2015). Further research is needed to test the possibility of obtaining specific FTIR calibrations for different type of cheese production to be used at dairy industry level.

\section{CONCLUSIONS}

In conclusion, modeling of $\mathrm{CF}$ has been found to be very useful in representing cheesemaking processes and understanding the effects of procedure modifications. The study confirmed the large effect on milk coagulation and $\mathrm{CF}$ of some cheesemaking conditions, such as process temperature, acidification, amount and type of rennet, and, to smaller degree, fat standardization. No appreciable effect resulted from lysozyme addition. These factors have been shown to affect not only coagulation and CF patterns, but also repeatability of the traits considered. In particular, reduction in temperature and acidification of the milk tended to decrease repeatability of the lactodynamographic tests. Lactodynamographic procedures are not internationally standardized, but generally reflect the production procedure of full-fat fresh cheeses. Questions have arisen about the usefulness of a standard lactodynamographic procedure to assess the aptitude of milk to be transformed into cheese using very different processes. Grana Padano, a partially skimmed, long-ripened, very hard cheese, was used as a case study to analyze the predictability of coagulation and $\mathrm{CF}$ traits under very different cheesemaking procedures. The results of the study showed that, although a combination of different variations may not change the average CF pattern of milk samples, repeatability may be lowered, and, in particular, correlations between procedures at the individual sample level are medium-to-good but never very high. The standard lactodynamographic procedure can 
only partially capture differences in the cheese making aptitudes of milk samples processed for long ripened, hard PDO cheeses made from partially skim milk. Although the standard procedure can be considered useful for research, animal's genetic improvement, and dairy industry, to obtain better predictability it should be adapted to the specific cheesemaking conditions, especially for research purposes. For the use in monitoring the production chain at level of dairy industry, further research seems needed to test the possible use of specific calibrations based on FTIR spectroscopy.

\section{ACKNOWLEDGMENTS}

This research was developed within the "Filigrana" Project funded by the Italian Ministry of Agriculture, Forestry and Food Politics (Rome, Italy; MiPAAF D.M. 25741/7303/11 of 01.12.11) as part of the Food Laboratory established under the project "Strengthening of the Facilities Supporting BiotechNology Research" of the Veneto Region (Italy; "RISIB" SMUPR project 4145: Regional Competitiveness and Job Creation; FESR $2007 / 2013$ Action 1.1.1). Moreover, this project was partially supported by the University of Padova (Ricerca Scientifica fondi quota EX 60\% - 60A08-5878/14).

\section{REFERENCES}

AIA (Italian Breeders Association). 2013. National production statistics. www.aia.it.

Ali, A. K. A., and G. E. Shook. 1980. An optimum transformation for somatic cell concentration in milk. J. Dairy Sci. 63:487-490.

Alipanah, M., and L. A. Kalashnikova. 2007. Influence of k-casein genetic variant on cheese making ability. J. Anim. Vet. Adv. 6:855-857.

ASPA Commission. 1995 Attitudine alla coagulazione. Metodo lattodinamografico. Pages 152-155 in Metodi di Analisi del Latte Delle Principali Specie di Interesse Zootecnico. Università degli Studi di Perugia, Perugia, Italy.

Bertoni, G., L. Calamari, and M. G. Maianti. 2001. Producing specific milk for specialty cheeses. Proc. Nutr. Soc. 60:231-246.

Bertoni, G., L. Calamari, M. G. Maianti, and B. Battistotti. 2005. Milk for protected denomination of origin (PDO) cheeses: I. The main required features. Pages 217-228 in Indicators of Milk and Beef Quality. J. F. Hocquette and S. Gigli, ed. EAAP Publication 112. Wageningen Academic Publishers, Wageningen, the Netherlands.

Bittante, G. 2011. Modeling rennet coagulation time and curd firmness of milk. J. Dairy Sci. 94:5821-5832.

Bittante, G., A. Cecchinato, N. Cologna, M. Penasa, F. Tiezzi, and M. De Marchi. 2011a. Factors affecting the incidence of first-quality wheels of Trentingrana cheese. J. Dairy Sci. 94:3700-3707.

Bittante, G., C. Cipolat-Gotet, F. Malchiodi, E. Sturaro, F. Tagliapietra, S. Schiavon, and A. Cecchinato. 2015. Effect of dairy farming system, herd, season, parity and days in milk on modeling of the coagulation, curd firming and syneresis of bovine milk. J. Dairy Sci. 98:2759-2274. http://dx.doi.org/10.3168/jds.2014-8909.

Bittante, G., N. Cologna, A. Cecchinato, M. De Marchi, M. Penasa, F. Tiezzi, I. Endrizzi, and F. Gasperi. 2011b. Monitoring of sensory attributes used in the quality payment system of Trentingrana cheese. J. Dairy Sci. 94:5699-5709.
Bittante, G., B. Contiero, and A. Cecchinato. 2013. Prolonged observation and modelling of milk coagulation, curd firming, and syneresis. Int. Dairy J. 29:115-123.

Bittante, G., M. Penasa, and A. Cecchinato. 2012. Invited review: Genetics and modeling of milk coagulation properties. J. Dairy Sci. 95:6843-6870.

Bonfatti, V., A. Cecchinato, L. Gallo, A. Blasco, and P. Carnier. 2011. Genetic analysis of detailed milk protein composition and coagulation properties in Simmental cattle. J. Dairy Sci. 94:5183-5193.

Bottazzi, V. 1976. Particolari aspetti della produzione del formaggio grana. I parte. Sci. Tecn. Latt. Cas. 27:239-260.

Bottazzi, V., B. Battistotti, F. Cappa, A. Rebecchi, S. Bertuzzi, and E. Brambilla. 1993. Germinazione delle spore di Clostridum ed azione del lisozima in formaggio grana. Sci. Tecn. Latt. Cas. 44:77-96.

Buchberger, J., and P. Dovč. 2000. Lactoprotein genetic variants in cattle and cheese making ability. Food Technol. Biotechnol. 38:91-98.

Calamari, L., G. Bertoni, M. G. Maianti, and B. Battistotti. 2005. Milk for protected denomination of origin (PDO) cheeses: II. The evaluation techniques of milk suitability. Pages 229-244 in Indicators of Milk and Beef Quality. J. F. Hocquette and S. Gigli, ed. EAAP Publication 112. Wageningen Academic Publishers, Wageningen, the Netherlands.

Caplan, Z., C. Melilli, and D. M. Barbano. 2013. Gravity separation of fat, somatic cells, and bacteria in raw and pasteurized milks. J. Dairy Sci. 96:2011-2019.

Caroli, A.. P. Bolla, G. Pagnacco, M. Rampilli, and L. Degano. 1990. Repeatability of milk clotting aptitude evaluated by lactodynamographic analysis. J. Dairy Res. 57:141-142.

Caroli, A., and L. Cauvin. 1999. Repeatability and reproducibility of the lactodinamographic analysis for the evaluation of bovine milk clotting aptitude. Zoot. Nutr. Anim. 25:219-227.

Castillo, M., J. A. Lucey, T. Wang, and F. A. Payne. 2006. Effect of temperature and inoculums concentration on gel microstructure, permeability and syneresis kinetics. Cottage cheese-type gels. Int. Dairy J. 16:153-163.

Cecchinato, A., C. Cipolat-Gotet, J. Casellas, M. Penasa, A. Rossoni, and G. Bittante. 2013. Genetic analysis of rennet coagulation time, curd-firming rate, and curd firmness assessed on an extended testing period using mechanical and near-infrared instruments. J. Dairy Sci. 96:50-62.

Cecchinato, A., M. De Marchi, L. Gallo, G. Bittante, and P. Carnier 2009. Mid-infrared spectroscopy predictions as indicator traits in breeding programs for enhanced coagulation properties of milk. J. Dairy Sci. 92:5304-5313.

Cecchinato, A., M. Penasa, M. De Marchi, L. Gallo, G. Bittante, and P. Carnier. 2011. Genetic parameters of coagulation properties, milk yield, quality, and acidity estimated using coagulating and noncoagulating milk information in Brown Swiss and HolsteinFriesian cows. J. Dairy Sci. 94:4205-4213.

Chessa, S., O. Bulgari, R. Rizzi, L. Calamari, S. Biffani, and A. M. Caroli. 2014. Selection for milk coagulation properties predicted by Fourier transform infrared spectroscopy in the Italian HolsteinFriesian . J. Dairy Sci. 97:4512-4521.

Cipolat-Gotet, C., A. Cecchinato, M. De Marchi, M. Penasa, and G. Bittante. 2012. Comparison between mechanical and near-infrared methods for assessing coagulation properties of bovine milk. J. Dairy Sci. 95:6806-6819.

CLAL. 2014. Italia: Produzioni di Formaggio Grana Padano. Accessed Oct. 20, 2014. http://www.clal.it/index.php?section=produzioni_ grana.

Cunningham, F., E. Proctor, and V. A. Goetsch. 1991. Egg-white lysozyme as a food preservative: An overview. Worlds Poult. Sci. J. $47: 141-163$.

Feligni, M., E. Brambati, S. Panelli, M. Ghitti, R. Sacchi, E. Capelli, and C. Bonacina. 2014. One-year investigation of Clostridium spp. occurrence in raw milk and curd of Grana Padano cheese by the automated ribosomial intergenic spacer analysis. Food Contr. 42:71-77.

Ferragina, A., G. de los Campos, A. Vazquez, A. Cecchinato, and G. Bittante. 2015. Bayesian regression models outperform partial 
least squares methods for prediction of milk components and technological properties. J. Dairy Sci. 98. In press.

Geer, S. R., and D. M. Barbano. 2014. The effect of immunoglobulins and somatic cells on the gravity separation of fat, bacteria, and spores in pasteurized whole milk. J. Dairy Sci. 97:2027-2038.

Hallen, E., T. Allmere, J. Naslund, A. Andren, and A. Lunden. 2007. Effect of genetic polymorphism of milk proteins on rheology of chymosin-induced milk gels. Int. Dairy J. 17:791-799.

Ikonen, T., K. Ahlfors, R. Kempe, M. Ojala, and O. Ruottinen. 1999. Genetic parameters for the milk coagulation properties and prevalence of noncoagulating milk in Finnish dairy cows. J. Dairy Sci. 82:205-214.

Ikonen, T., S. Morri, A. M. Tyriseva, O. Ruottinen, and M. Ojala. 2004. Genetic and phenotypic correlations between milk coagulation properties, milk production traits, somatic cell count, casein content, and pH of milk. J. Dairy Sci. 87:458-467.

ISO-IDF. 2004. Milk - Determination of casein-nitrogen content-Part 1: Indirect method. International Standard ISO 17997-1 and IDF 29-1:2004. ISO, Geneva, Switzerland and IDF, Brussels, Belgium.

ISO-IDF (International Organization for Standardization and International Dairy Federation). 2010. Milk-Determination of fat content. International Standard ISO 1211 and IDF 1:2010. ISO, Geneva, Switzerland and IDF, Brussels, Belgium.

ISO-IDF. 2014. Milk and milk products-Determination of nitrogen content-Part 1: Kjeldahl principle and crude protein calculation. International Standard ISO 8968-1 and IDF 1:2014. ISO, Geneva, Switzerland and IDF, Brussels, Belgium.

Jensen, H. B., J. W. Holland, N. A. Poulsen, and L. B. Larsen. 2012. Milk protein genetic variants and isoforms identified in bovine milk representing extremes in coagulation properties. J. Dairy Sci. 95:2891-2903.

Johnson, M. E., C. M. Chen, and J. J. Jaeggi. 2001. Effect of rennet coagulation time on composition, yield, and quality of reduced-fat Cheddar cheese. J. Dairy Sci. 84:1027-1033.

Julien, M. C., P. Dion, C. Lafrenière, H. Antoun, and P. Drouin. 2008. Sources of clostridia in raw milk on farms. Appl. Environ. Microbiol. 74:6348-6357.

Klandar, A. H., A. Lagaude, and D. Chevalier-Lucia. 2007. Assessment of the rennet coagulation of skim milk: A comparison of methods. Int. Dairy J. 17:1151-1160.

Lagoueyte, N., J. Lablee, A. Lagaude, and B. Tarodo de La Fuente. 1994. Temperature affects microstructure of renneted milk gel. J. Food Sci. 59:956-959.

Law, B. A., and A. Y. Tamine, ed. 2010. Technology of Cheesemaking. 2nd ed. Wiley-Blackwell, John Wiley \& Sons Ltd., Chicester. UK.

Lucey, J. A. 2002. Formation and physical properties of milk protein gels. J. Dairy Sci. 85:281-294.

Macheboeuf, D., J. B. Coulon, and P. D'Hour. 1993. Effect of breed, protein genetic variants and feeding on cow's milk coagulation properties. J. Dairy Res. 60:43-54.

Malacarne, M., A. Summer, P. Formaggioni, P. Franceschi, S. Sandri, M. Pecorari, P. Vecchia, and P. Mariani. 2008. Dairy maturation of milk used in the manufacture of Parmigiano-Reggiano cheese: Effects on physico-chemical characteristics, rennet coagulation aptitude and rheological properties. J. Dairy Res. 75:218-224.

Malchiodi, F., A. Cecchinato, M. Penasa, C. Cipolat-Gotet, and G. Bittante. 2014. Milk quality, coagulation properties and curd firmness modeling of purebred Holsteins and first- and second-generation crossbred cows from Swedish Red, Montbéliarde, and Brown Swiss bulls. J. Dairy Sci. 97:4530-4541.

Mariani, P., and B. Battistotti. 1999. Milk quality for cheesemaking. Recent progress in animal production science. Pages 499-516 in Proc. APSA XIII Congress, Piacenza, Italy. Franco Angeli s.r.l., Milan, Italy.
Martin, B., J.-F. Chamba, J.-B. Coulon, and E. Perreard. 1997. Effect of milk chemical composition and clotting characteristics on chemical and sensory properties of Reblochon de Savoie cheese. J. Dairy Res. 64:157-162.

McMahon, D. J., and R. J. Brown. 1982. Evaluation of Formagraph for comparing rennet solutions. J. Dairy Sci. 65:1639-1642.

Mishra, R., S. Govindasamy-Lucey, and J. A. Lucey. 2005. Rheological properties of rennet-induced gels during the coagulation and cutting process: Impact of processing conditions. J. Texture Stud. $36: 190-212$.

Nájera, A. I., M. de Renobales, and L. I. R. Barron. 2003. Effects of $\mathrm{pH}$, temperature, $\mathrm{CaCl}_{2}$ and enzyme concentrations on the rennet clotting properties of milk: A multifactorial study. Food Chem. 80:345-352.

Okigbo, L. M., G. H. Richardson, R. J. Brown, and C. A. Ernstrom. 1985. Effects of $\mathrm{pH}$, calcium chloride, and chymosin concentration on coagulation properties of abnormal and Normal milk. J. Dairy Sci. 68:2527-2533.

Pazzola, M., M. L. Dettori, C. Cipolat-Gotet, A. Cecchinato, G. Bittante, and G. M. Vacca. 2014. Phenotypic factors affecting coagulation properties of milk from Sarda ewes. J. Dairy Sci. 97:72477257.

Pecorari, M. 1994. Parmigiano-Reggiano, innovazione e tipicità. Alimentaria (Suppl. 6) 41:20-26.

Pecorari, M., G. Gambini, P. Reverberi, and A. Caroli. 2003. L'influenza di alcuni fattori tecnologici sulla glicolisi del Parmigiano-Reggiano. Sci. Tecn. Latt. Cas. 54(Suppl. 4):287-299.

Sousa, M. J., T. Ardo, and P. L. H. McSweeney. 2001. Advances in the study of proteolysis during cheese ripening. Int. Dairy J. $11: 327-345$

Sturaro, E., E. Marchiori, G. Cocca, M. Penasa, M. Ramanzin, and G. Bittante. 2013. Dairy systems in mountainous areas: Farm animal biodiversity, milk production and destination, and land use. Livest. Sci. 158:157-168.

Summer, A., P. Franceschi, A. Bollini, P. Formaggioni, F. Tosi, and P. Mariani. 2003. Seasonal variations of milk characteristics and cheesemaking losses in the manufacture of Parmigiano-Reggiano cheese. Vet. Res. Commun. 27(Suppl. 1):663-666.

Tedeschi, G., F. Tosi, and M. Pecorari. 1993. La tecnologia di caseificazione del Parmigiano-Reggiano: Variabilità e valori analitici sul latte, cagliata e siero. Sci. Tecn. Latt. Cas. 44:327.

Tyrisevä, A.-M., T. Ikonen, and M. Ojala. 2003. Repeatability estimates for milk coagulation traits and non-coagulation of milk in Finnish Ayrshire cows. J. Dairy Res. 70:91-98.

Tyrisevä, A.-M., T. Vahlsten, O. Ruottinen, and M. Ojala. 2004. Noncoagulation of milk in Finnish Ayrshire and Holstein-Friesian cows and effect of herds on milk coagulation ability. J. Dairy Sci. 87:3958-3966.

Vallas, M., H. Bovenhuis, T. Kaart, K. Parna, H. Kiiman, and E. Pärna. 2010. Genetic parameters for milk coagulation properties in Estonian Holstein cows. J. Dairy Sci. 93:3789-3796.

Walsh, C. D., T. P. Guinee, W. D. Reville, D. Harrington, J. J. Murphy, B. T. O'Kennedy, and R. J. Fitzgerald. 1998. Influence of k-casein genetic variant on rennet gel microstructure, Cheddar cheesemaking properties and casein micelle size. Int. Dairy J. 8:707-714

Wedholm, A., L. B. Larsen, H. Lindmark-Mansson, A. H. Karlsson, and A. Andren. 2006. Effect of protein composition on the cheesemaking properties of milk from individual dairy cows. J. Dairy Sci. 89:3296-3305

Zannoni, M., and M. Nanni. 1982. Indagine sull'affioramento del grasso del latte in caseificio. Sci. Tecn. Latt. Cas. 33:493-506. 